\title{
Effect of Cross-Rolling on Microstructure, Texture and Magnetic Properties of Non- Oriented Electrical Steels
}

\author{
Jitendra Mishra ${ }^{a}$, Sandeep Sahni ${ }^{a}$, Ramakrushna Sabat ${ }^{b}$, Vijay Devidas Hiwarkar ${ }^{\prime}$, Santosh Kumar Sahoo ${ }^{a *}$ \\ a Department of Metallurgical \& Materials Engineering, National Institute of Technology Rourkela- \\ NITR, Rourkela, 769008, Odisha, India \\ ${ }^{b}$ Department of Materials Engineering, Indian Institute of Science - IISc, Bangalore, 560012, \\ Karnataka, India \\ ${ }^{c}$ Department of Materials Engineering, Defence Institute of Advanced Technology-DIAT, Pune, \\ 411025, Maharashtra, India
}

Received: June 9, 2016; Revised: October 11, 2016; Accepted: November 21, 2016

\begin{abstract}
Hot rolled non-oriented electrical steel samples were subjected to cold cross-rolling of $80 \%$ reduction in thickness. The cross-rolled samples were then annealed at 650,750 and $850{ }^{\circ} \mathrm{C}$ for $1 \mathrm{hr}, 2$ hrs and $4 \mathrm{hrs}$ respectively. The role of cross-rolling on microstructure, texture and magnetic properties of the samples after annealing has been investigated. Two different samples were used for the present investigation - one had higher Al content (sample S1) while the other had higher C, Si, Mn, P and S content (sample S2). It was observed that the sample S1 had higher grain size compared to sample S2 after annealing. The cross-rolling was observed to be controlled the texture developments in the samples and it was found that the texture factor was identical in all directions of the sample. The core losses in the samples were found to be decreased with increasing grain size of the samples.
\end{abstract}

Keywords: Electrical Steels, Cross-Rolling, Annealing, Texture, Core Loss

\section{Introduction}

Non-oriented electrical steels are widely used in electrical generators and motors where the magnetic field is important in all directions ${ }^{1-3}$. To achieve adequate magnetic properties in all directions, both grain size and texture have been controlled through different thermo-mechanical processing of these steels ${ }^{4-7}$. An optimum grain size is essential for minimum watt loss in the material - for example, the optimum grain sizes are 100 and 150 micron for 1.85 and $3.2 \%$ Si steels respectively $^{8}$. Texture components like $(001)<$ uvw $>$ and (111) $<$ uvw $>$ are considered respectively as good and bad texture components from magnetic properties point of view $^{9,10}$. However, various texture components other than $(001)<$ uvw $>$ texture of these steels i.e. goss $\{110\}<100>$, cube $\{100\}<001>$ and eta $\{h \mathrm{hl}\}<100>$ are also good texture components from magnetic properties viewpoint ${ }^{11}$. At present no method is feasible for the production of $(001)<\mathrm{uvw}>$ texture in all directions. Therefore, in the entire world isotropic non-oriented steels with multi-component texture have been developed for this purpose. Multistep cross-rolling (MSCR) has been observed to be an efficient method to randomize the texture of a material ${ }^{12-15}$. During MSCR, the material is rotated by $90^{\circ}$ in the intermittent steps of the rolling ${ }^{16}$. In the present study the effect of MSCR processing and subsequent annealing of hot rolled non-oriented electrical steels on microstructure, texture and magnetic properties of these steels have been investigated.

\footnotetext{
* e-mail: sursahoo@gmail.com
}

\section{Experimental Details}

\subsection{Material and Sample Preparation}

Hot rolled steels of $2.3 \mathrm{~mm}$ thickness were used as the starting material for the present study. Two different samples were used for the present investigation - sample S1, had higher Al content and sample S2 which had higher $\mathrm{C}, \mathrm{Si}$, $\mathrm{Mn}, \mathrm{P}$ and S content. The chemical composition (in wt.\%) of the samples is shown in Table 1. The steels were subjected to multi-step cross-rolling (MSCR) in a laboratory rolling mill down to $80 \%$ reduction in thickness. During each steps of MSCR, true strain was maintained at $10 \%$. The MSCR samples were subjected to annealing at 650,750 and $850^{\circ} \mathrm{C}$ for $1 \mathrm{hr}, 2 \mathrm{hrs}$ and $4 \mathrm{hrs}$ respectively. The samples were then metallographically polished for subsequent characterizations.

\subsection{Optical Microscopy}

Optical microstructures of the samples were characterized using a Zeiss AxioCam ERc 5s image analyzer. The samples were etched with nital solution for the microstructural analysis.

\subsection{X-Ray Diffraction (XRD)}

XRD was carried out in a Bruker D8-Advance system using Co $\mathrm{K}_{\alpha}$ radiation. Three pole figures, (110), (200) and (211), were measured on the ND plane containing the RD-TD direction. RD corresponds to the rolling direction whereas ND and TD correspond to the normal and transverse 
Table 1: Chemical composition (in wt.\%) of steel samples used in the present study. The balance amount was being Fe.

\begin{tabular}{lcccccccccc}
\hline Sample & $\mathrm{C}$ & $\mathrm{Si}$ & $\mathrm{Mn}$ & $\mathrm{P}$ & $\mathrm{S}$ & $\mathrm{Al}$ & $\mathrm{Cr}$ & $\mathrm{Mo}$ & $\mathrm{Ni}$ & $\mathrm{Cu}$ \\
\hline $\mathrm{S} 1$ & 0.0376 & 1.45 & 0.305 & 0.0201 & 0.018 & 0.0965 & 0.007 & 0.0021 & 0.0097 & 0.012 \\
$\mathrm{~S} 2$ & 0.0390 & 1.52 & 0.350 & 0.0216 & 0.020 & 0.0525 & - & - & - & - \\
\hline
\end{tabular}

direction respectively. Orientation distribution functions (ODFs) were calculated using the Labotex 3.0 software $^{17}$. Using the software, volume fractions of different texture components were estimated through integration method with a $15^{\circ}$ tolerance on the deviation from the ideal orientation(s).

\subsection{Magnetic Measurements}

Magnetic measurements were carried out on Brockhaus MPG 200 instrument. The core losses at $1.5 \mathrm{~T}$ and $50 \mathrm{~Hz}$ were obtained along RD of the samples. The samples were measured on single sheet tester of size $210 \mathrm{~mm} \times 210 \mathrm{~mm}$. For one condition three samples were measured in order to get the accuracy of the measurement.

\section{Results}

Figures 1 and 2 respectively show the optical microstructures of sample S1 and sample S2 at different conditions of annealing. A near equiaxed grains were observed in both the samples. However, a distinct bimodal distribution of grains was observed during annealing of the sample S1 at lower temperature $\left(650^{\circ} \mathrm{C}\right)$ and at higher temperature of annealing, it had abnormal grain growth. A regular increase in grain size as a function of both annealing temperature and annealing time was observed in the samples after annealing. Figure 3 shows the average grain size of the samples at different annealing conditions. The rate of grain growth was relatively higher when annealed at $850{ }^{\circ} \mathrm{C}$. Also the sample S1 had higher grain size than that of sample S2 after annealing.

Figures 4 and 5 respectively show the ODFs, at constant $\varphi_{2}=45^{\circ}$, of samples S1 and S2 at different conditions of annealing. It may be observed that the $\gamma$-fiber was distinct in sample S2. However, in sample S1 the fiber was not clear except during annealing at $650{ }^{\circ} \mathrm{C}$, and at $850{ }^{\circ} \mathrm{C}$ for $2 \mathrm{hrs}$ of annealing time. The volume fraction of texture factor i.e. $(111)<u v w>/(001)<u v w>{ }^{10}$ as a function of annealing temperature and time in samples $\mathrm{S} 1$ and $\mathrm{S} 2$ are shown in Figure 6 . The following observations may be obtained from Figure 6:

- At $650{ }^{\circ} \mathrm{C}$ annealing temperature: The texture factor decreased, though not significantly, as a function of annealing time for sample $\mathrm{S} 1$. Whereas in case of sample S2, it was increased till $2 \mathrm{hrs}$ of annealing time and the decreased on further increasing the annealing time of $4 \mathrm{hrs}$.

- At $750{ }^{\circ} \mathrm{C}$ annealing temperature: For sample $\mathrm{S} 1$, the texture factor was decreased till $2 \mathrm{hrs}$ of annealing time and then increased at $4 \mathrm{hrs}$ of annealing time. However, the texture factor was decreased with increasing annealing time may be observed in sample $\mathrm{S} 2$.

- At $850{ }^{\circ} \mathrm{C}$ annealing temperature: An increased texture factor with increased annealing time was observed in sample S1. However, in sample S2 the texture factor was initially decreased till $2 \mathrm{hrs}$ of annealing time and then increased on further increasing the annealing time of $4 \mathrm{hrs}$.

As shown in Table 2, it can be observed that the texture factor along all other directions were approximately similar to the values observed along $\mathrm{RD}$.

Figure 7 shows the core losses of the samples at different annealing conditions. It was observed that the core losses were decreased with increasing the time of annealing. Also the sample S1 had relatively lower core losses compared to that of sample $\mathrm{S} 2$.

\section{Discussion}

The magnetic properties of electrical steels largely depend on the chemical composition, crystallographic texture and grain size $\mathrm{e}^{4,10,18}$. The elements such as $\mathrm{P}, \mathrm{Si}, \mathrm{Al}$ and $\mathrm{Mn}$ are generally added to the steels to improve the resistivity $9,10,18$. The other major elements such as $\mathrm{C}$ and $\mathrm{S}$ affect the magnetic properties of the steels and these contents should be lower for better magnetic properties of the steels. It has also been reported that the harmful effects of $\mathrm{C}$ and $\mathrm{S}$ can be minimized through second phase precipitation ${ }^{5,19}$. The alloying elements also help in controlling the texture of the electrical steels through growth inhibition ${ }^{18}$. Mn is a good example of generating growth inhibitors during annealing of non-oriented electrical steels ${ }^{18}$. This might be the reason for the sample S2 to have lower grain size compared to sample S1 after annealing. Also it was observed that the abnormality in grain growth was seen in sample S1 (Figure 1) although sample S1 higher Al content which also can generate growth inhibitors ${ }^{5}$. However, Al has been observed to be detrimental to the workability of the samples and this could affect the stored energy of the sample during cold rolling which affects the subsequent grain growth of the sample.

Controlling the crystallographic texture and grain size of these steels mostly depends on the thermo-mechanical processing steps during the production. It has been found that an optimum grain size and low texture factor, (111)<uvw $>$ / $(001)<\mathrm{uvw}>$, is required for better magnetic properties of electrical steels ${ }^{10}$. However, unlike CRGO (cold rolled grain 

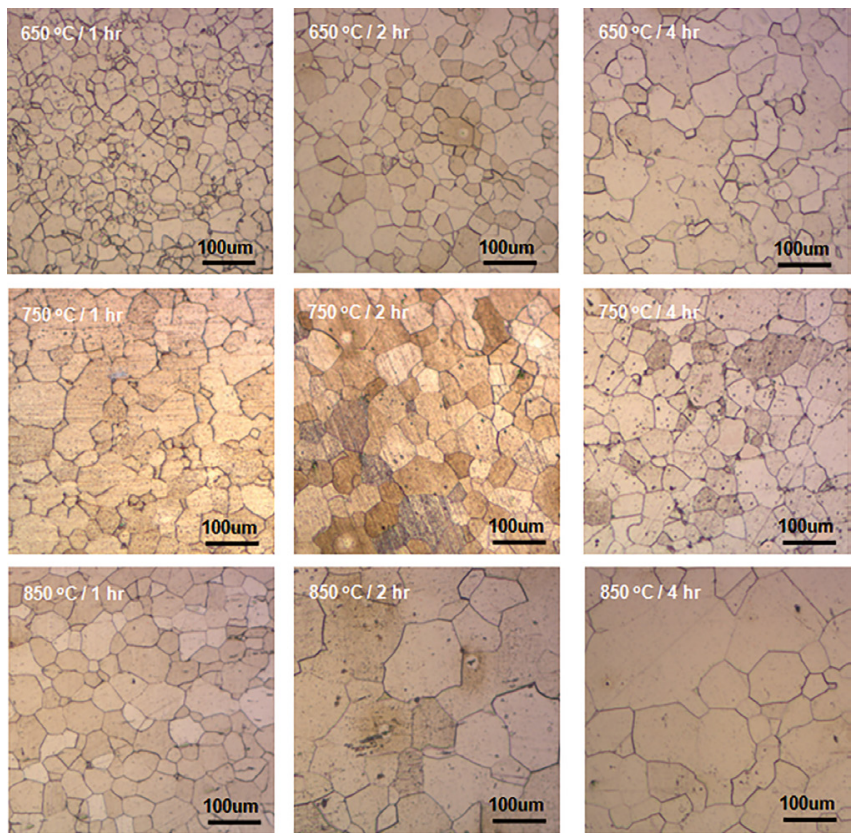

Figure 1: Optical microstructures of the sample $\mathrm{S} 1$ at different annealing conditions.
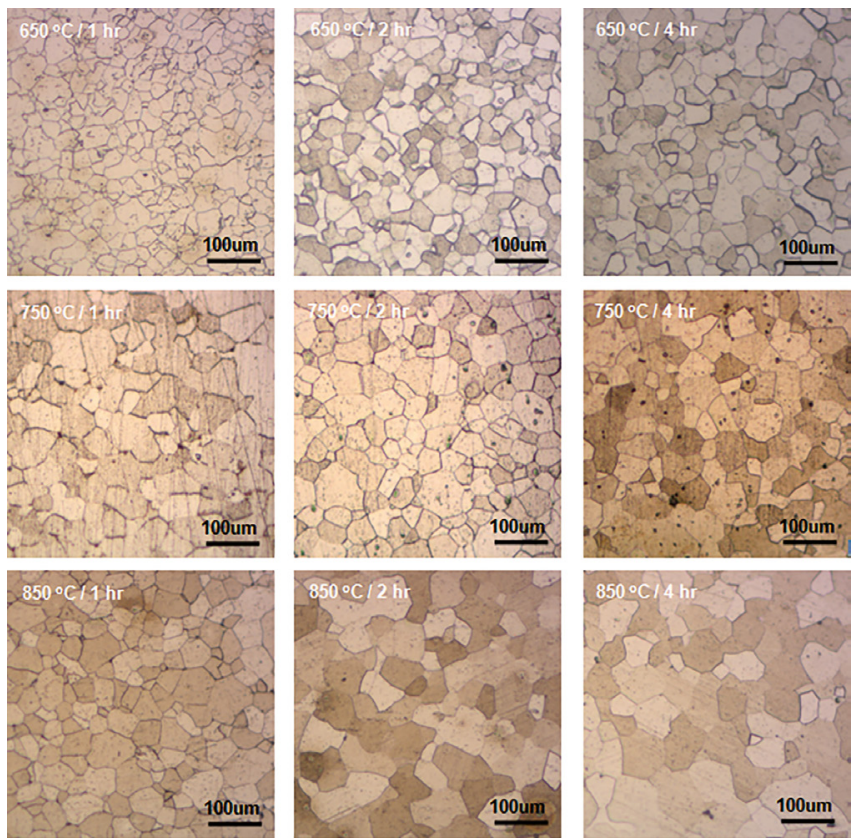

Figure 2: Optical microstructures of the sample S2 at different annealing conditions.

oriented) electrical steels where ideal texture is required along one direction/orientation, CRNO (cold rolled nonoriented) electrical steels the ideal texture is required in all direction. The present study is an attempt to weaken/ randomize the texture of the steels rather than improving the ideal texture in all directions. Cross-rolling has been a successful method to weaken the texture of cubic metals ${ }^{12-15}$. This was also observed in the present study which showed that the texture factor was identical in all directions of the samples (Table 2). The possible explanation for the formation of suitable recrystallization textures can be attributed to a combination of oriented nucleation and oriented growth, deformation accumulated stored energy, geometric softening and orientation pinning ${ }^{18,20,21}$. In the present study, however, the mechanism of recrystallization texture development is not debatable as the texture factor in the samples was not 

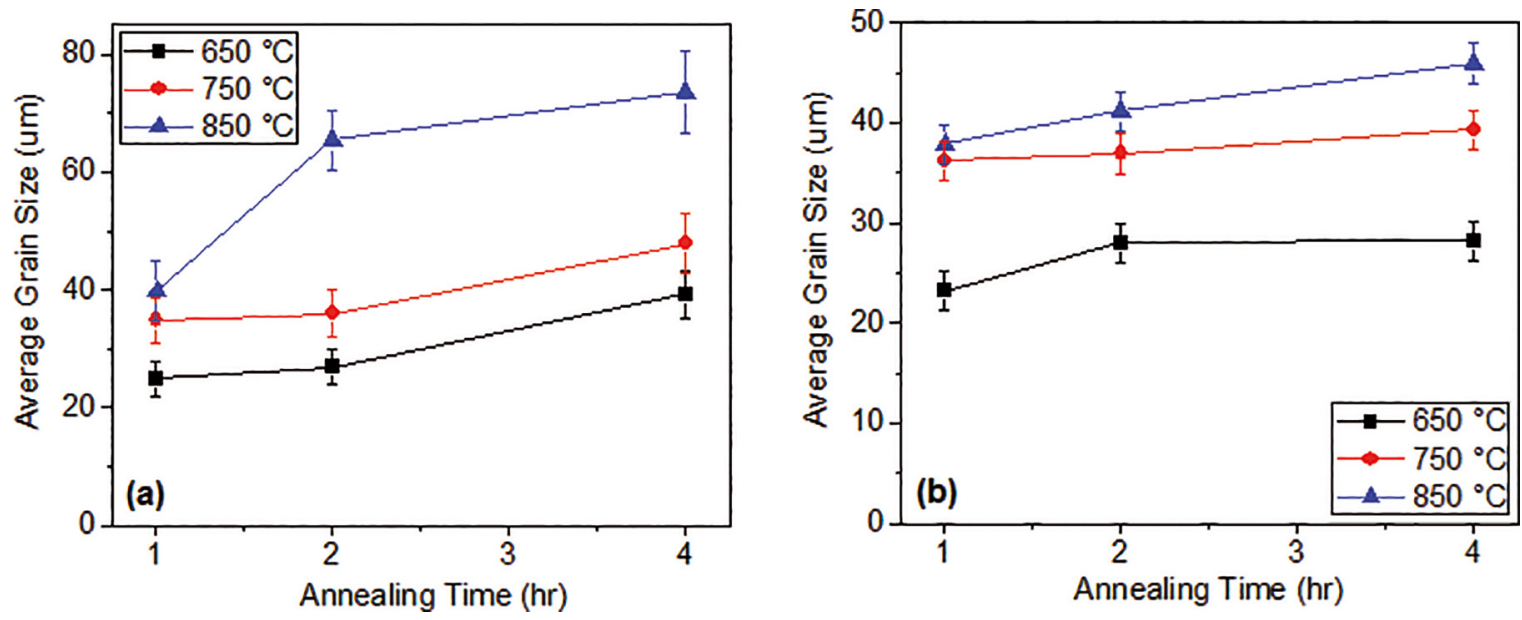

Figure 3: Average grain size of the samples as a function of temperature and time of annealing: (a) sample S1 and (b) sample S2.
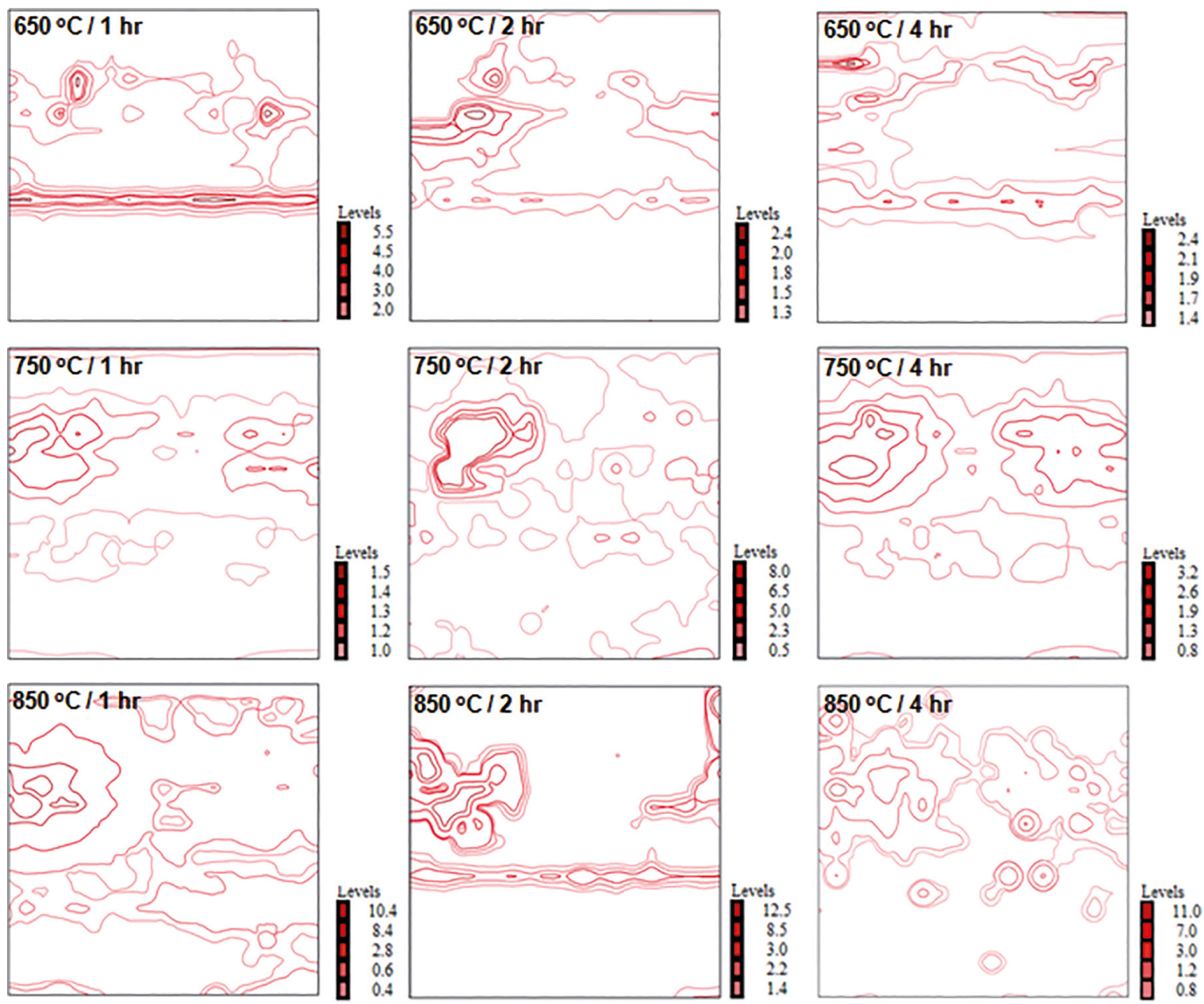

Figure 4. ODFs, at constant $\varphi_{2}=45^{\circ}$, of sample $\mathrm{S} 1$ at different annealing conditions.

very different (Figure 6, Table 2). The significant increase in texture factor of sample $\mathrm{S} 1$ annealed at $850^{\circ} \mathrm{C}$ for $2-4$ hrs of annealing time (Figure 6a) may be attributed to the oriented growth mechanism (Figure 1). However, the increase in texture factor of sample $\mathrm{S} 2$ annealed at $650^{\circ} \mathrm{C}$ for $2 \mathrm{hrs}$ of annealing time (Figure 6b) could be attributed to the combination of different recrystallization texture mechanisms ${ }^{21}$. 

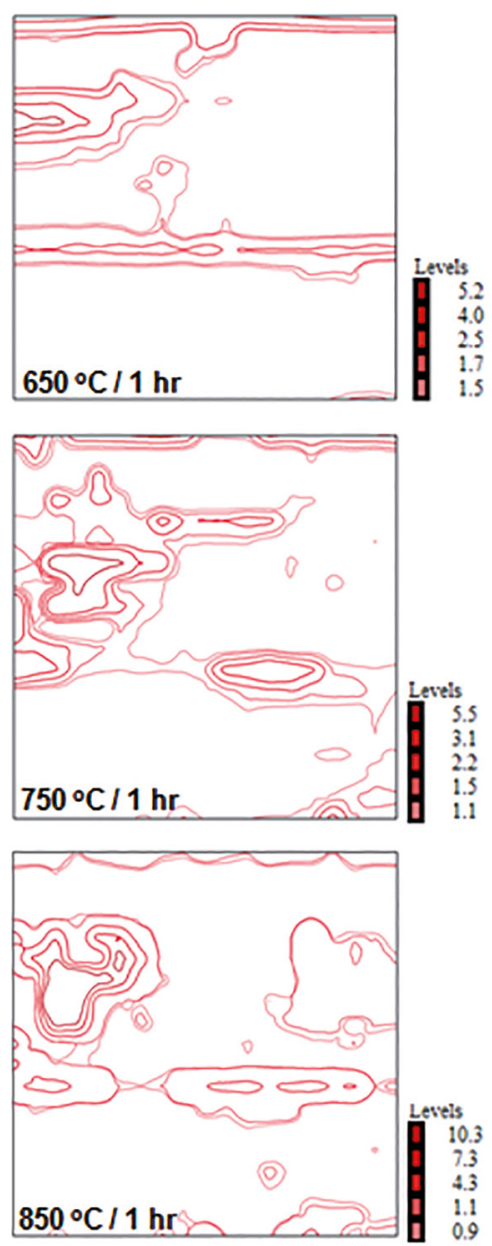
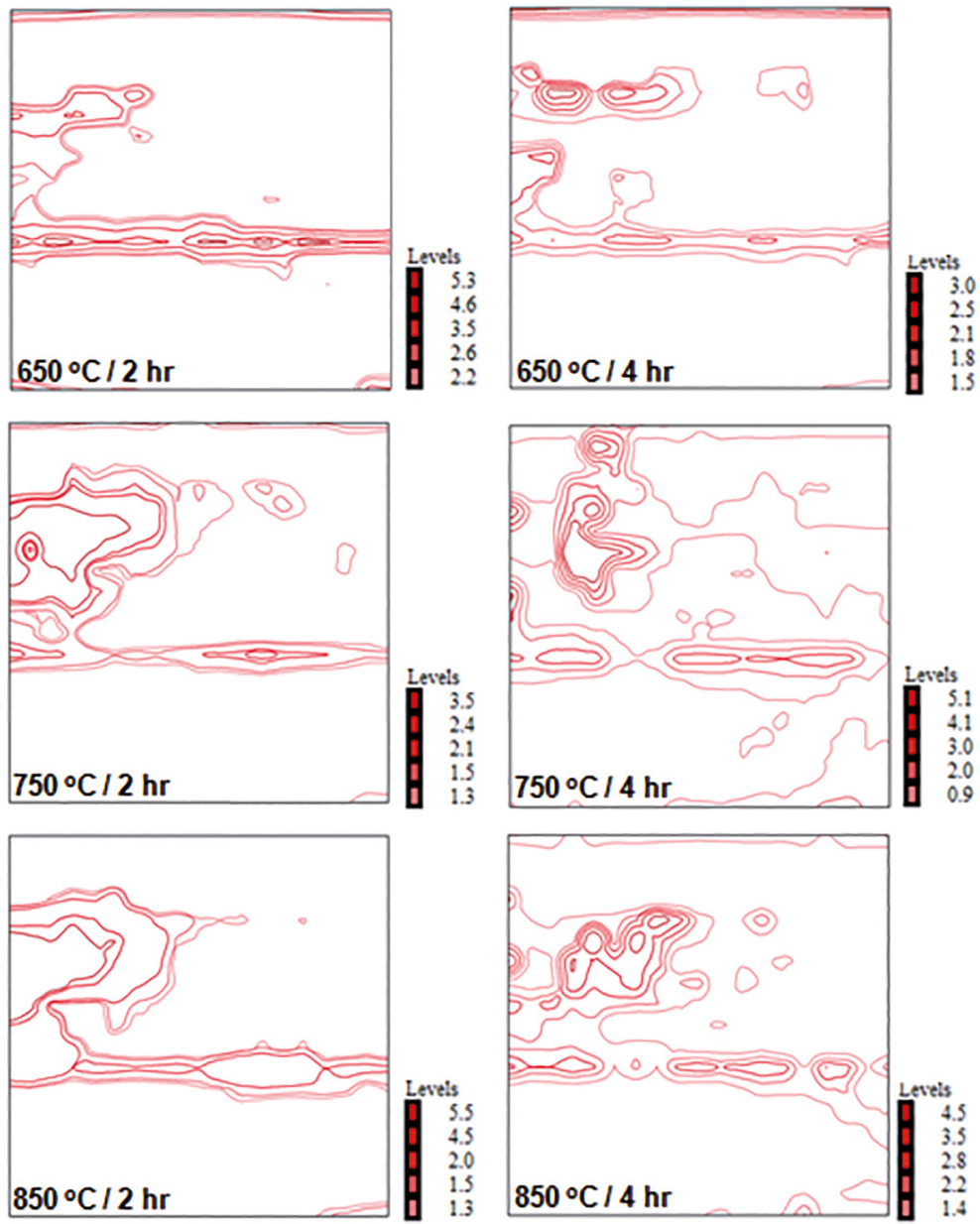

Figure 5: ODFs, at constant $\varphi_{2}=45^{\circ}$, of sample S2 at different annealing conditions.
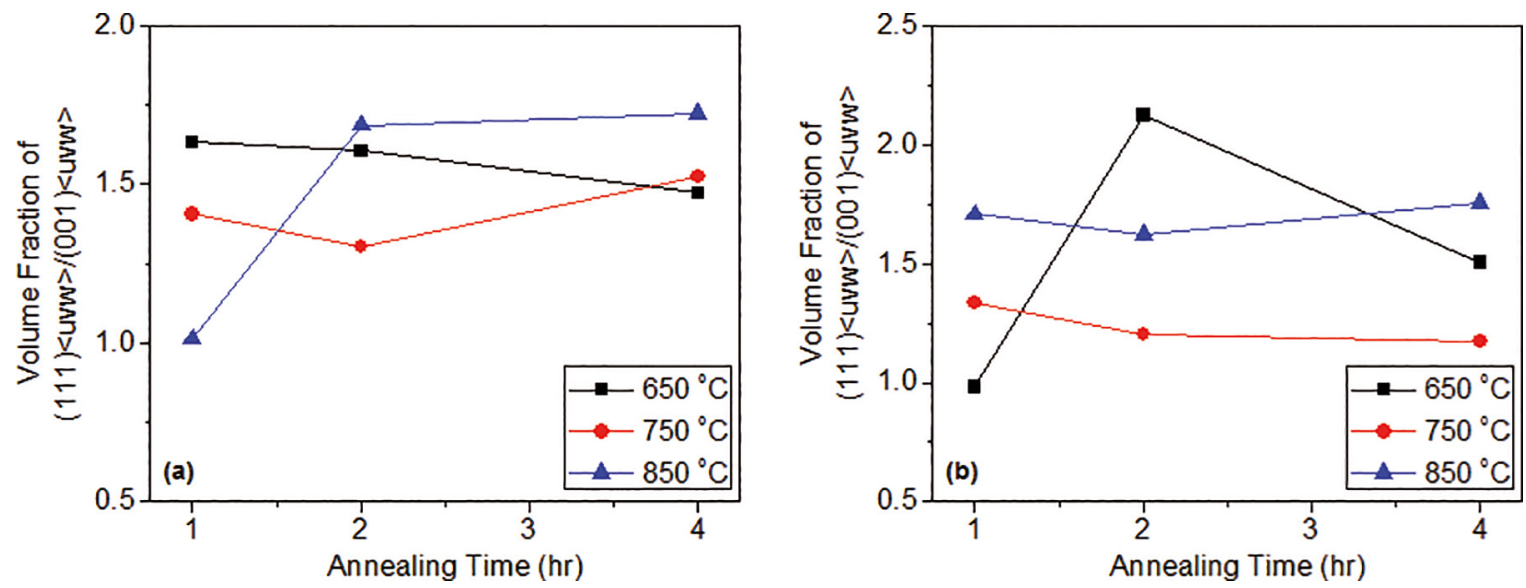

Figure 6: Volume fraction of texture factor i.e. $(111)<u v w>/(001)<u v w>$ as a function of annealing time at different temperatures of annealing for: (a) sample S1 and (b) sample S2.

The magnetic property of the samples, represented by core losses, was found to be dependent mainly on the average grain size of the samples although texture factor was also important (Figures 3,6 and 7). The higher the grain size of the sample lowered the core losses in the sample. It also indicated that the abnormality in grain growth in the sample S1 was not detrimental from the magnetic property viewpoint. 
Table 2: Texture factor of the samples as a function of sample orientation.

\begin{tabular}{|c|c|c|c|c|c|c|c|c|c|c|c|c|c|c|c|c|c|}
\hline \multirow{3}{*}{$\begin{array}{l}\begin{array}{l}\text { Annealing } \\
\text { Condition }\end{array} \\
\text { Temp. }\left({ }^{\circ} \mathrm{C}\right)\end{array}$} & \multicolumn{17}{|c|}{ Texture Factor at different sample orientation (w.r.t the rolling direction) } \\
\hline & \multicolumn{8}{|c|}{ Sample S1 } & \multicolumn{9}{|c|}{ Sample S2 } \\
\hline & $\begin{array}{l}\text { Time } \\
\text { (hrs) }\end{array}$ & $0^{\circ}$ & $45^{\circ}$ & $90^{\circ}$ & $135^{\circ}$ & $180^{\circ}$ & $225^{\circ}$ & $270^{\circ}$ & $315^{\circ}$ & $0^{\circ}$ & $45^{\circ}$ & $90^{\circ}$ & $135^{\circ}$ & $180^{\circ}$ & $225^{\circ}$ & $270^{\circ}$ & $315^{\circ}$ \\
\hline \multirow{3}{*}{650} & 1 & 1.63 & 1.62 & 1.64 & 1.62 & 1.64 & 1.62 & 1.65 & 1.63 & 0.98 & 0.96 & 0.97 & 0.98 & 0.97 & 0.97 & 0.97 & 0.96 \\
\hline & 2 & 1.61 & 1.61 & 1.57 & 1.60 & 1.61 & 1.55 & 1.61 & 1.55 & 2.12 & 2.11 & 2.11 & 2.11 & 2.14 & 2.10 & 2.11 & 2.12 \\
\hline & 4 & 1.47 & 1.47 & 1.47 & 1.48 & 1.47 & 1.47 & 1.48 & 1.47 & 1.50 & 1.50 & 1.48 & 1.48 & 1.48 & 1.49 & 1.49 & 1.48 \\
\hline \multirow{3}{*}{750} & 1 & 1.41 & 1.29 & 1.31 & 1.32 & 1.32 & 1.33 & 1.32 & 1.27 & 1.33 & 1.32 & 1.32 & 1.34 & 1.32 & 1.32 & 1.32 & 1.32 \\
\hline & 2 & 1.30 & 1.31 & 1.30 & 1.31 & 1.30 & 1.31 & 1.31 & 1.30 & 1.20 & 1.18 & 1.19 & 1.18 & 1.20 & 1.19 & 1.19 & 1.19 \\
\hline & 4 & 1.52 & 1.52 & 1.49 & 1.46 & 1.53 & 1.47 & 1.50 & 1.49 & 1.18 & 1.17 & 1.16 & 1.16 & 1.17 & 1.17 & 1.15 & 1.16 \\
\hline \multirow{3}{*}{850} & 1 & 1.01 & 1.01 & 1.00 & 1.01 & 1.01 & 1.01 & 1.01 & 1.02 & 1.71 & 1.69 & 1.68 & 1.70 & 1.68 & 1.70 & 1.69 & 1.68 \\
\hline & 2 & 1.69 & 1.66 & 1.67 & 1.70 & 1.70 & 1.65 & 1.68 & 1.68 & 1.62 & 1.69 & 1.65 & 1.70 & 1.65 & 1.72 & 1.64 & 1.72 \\
\hline & 4 & 1.72 & 1.72 & 1.70 & 1.72 & 1.71 & 1.71 & 1.71 & 1.70 & 1.76 & 1.74 & 1.74 & 1.76 & 1.72 & 1.71 & 1.74 & 1.76 \\
\hline
\end{tabular}
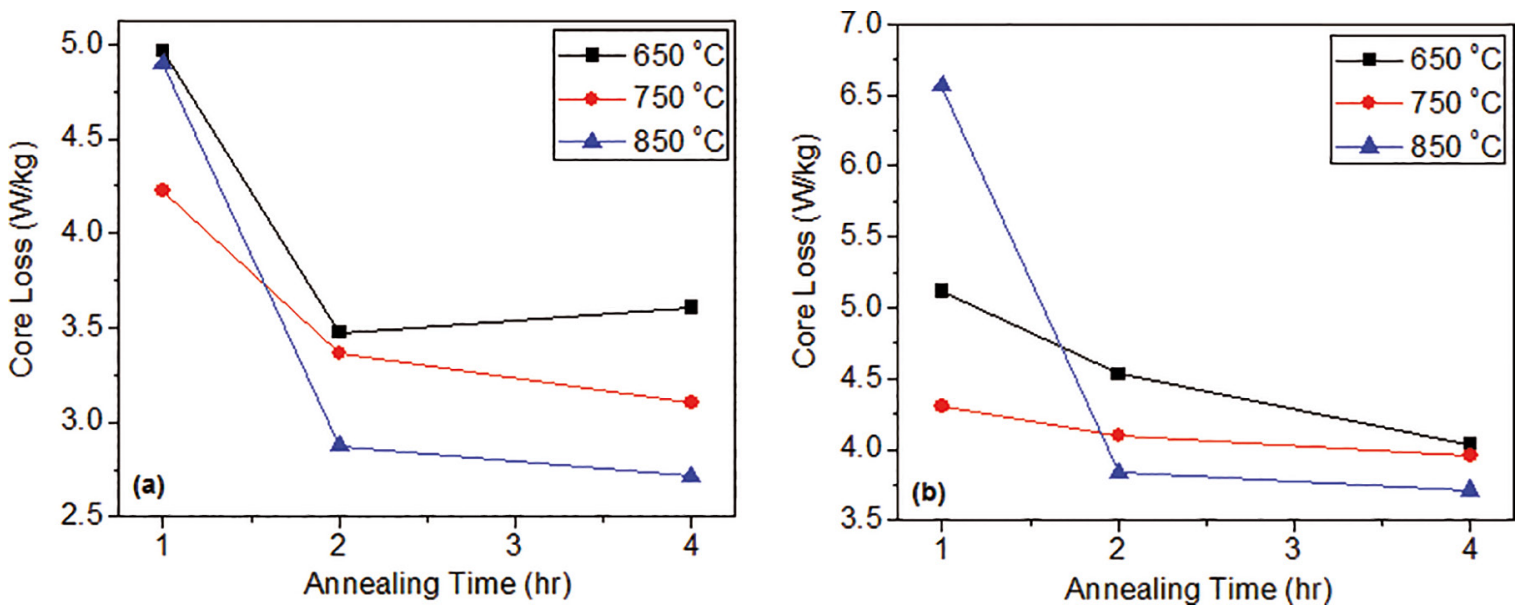

Figure 7: Core losses as a function of annealing temperature and annealing time for: (a) sample S1 and (b) sample S2. The core loss of the sample S1 before annealing was $12.17 \mathrm{~W} / \mathrm{kg}$ and that of sample S2 before annealing was $14.183 \mathrm{~W} / \mathrm{kg}$.

\section{Summary}

In the present study, the effect of chemistry and crossrolling on the microstructure, texture and magnetic properties of non-oriented electrical steels have been investigated. It was found that the electrical steel sample with higher Mn content showed normal grain growth whereas the sample with higher Al content showed abnormal grain growth during annealing of the samples. The cross-rolling prior to annealing of the samples had a significant effect on the texture developments in the samples and the samples had similar texture factor in all directions of the samples. It was also observed that the samples with higher grain size had lower core losses.

\section{Acknowledgement}

The authors would like to thank Prof. S. Suwas of IISc Bangalore for conducting rolling of the samples in his laboratory.

\section{References}

1. Moses AJ. Electrical steels: past, present and future developments. IEE Proceedings A - Physical Science, Measurement and Instrumentation, Management and Education. 1990;137(5):233-245.

2. Lyudkoushy G, Rastogi PK, Bala M. Nonoriented Electrical Steels. JOM. 1986;38(1):18-26.

3. Matsumura K, Fukuda B. Recent developments of non-oriented electrical steel sheets. IEEE Transactions on Magnetics. 1984;20(5):1533-1538.

4. Kestens L, Jacobs S. Texture control during the manufacturing of nonoriented electrical steels. Texture, Stress, and Microstructure. 2008;2008:173083.

5. Park JT, Szpunar JA, Kim JK. Texture development during final annealing in nonoriented electrical steels. Materials Science Forum. 2005;495-497:471-476.

6. Paepe AD, Eloot K, Dilewijns J, Standaert C. Effect of hot rolling parameters on the magnetic properties of a low-silicon ultra-low-carbon steel. Journal of Magnetism and Magnetic Materials. 1996;160:129-130. 
7. Ros-Yañez T, Houbaert Y, Fischer O, Schneider J. Production of high silicon steel for electrical applications by thermomechanical processing. Journal of Materials Processing Technology. 2003;141(1):132-137.

8. Prusty D, Pradhan HK, Hiwarkar VD, Sahoo SK. Directional Properties of Cold Rolled Non-oriented Electrical Steel Sheets. Transactions of the Indian Institute of Metals. 2014;67(1):131-135.

9. Shimanaka H, Ito Y, Matsumara K, Fukuda B. Recent development of non-oriented electrical steel sheets. Journal of Magnetism and Magnetic Materials. 1982;26(1-3):57-64.

10. PremKumar R, Samajdar I, Viswanathan NN, Singal V, Seshadri V. Relative effect(s) of texture and grain size on magnetic properties in a low silicon non-grain oriented electrical steel. Journal of Magnetism and Magnetic Materials. 2003;264(1):75-85.

11. Chang SK. Texture effects on magnetic properties in highalloyed non-oriented electrical steels. Metal Science and Heat Treatment. 2007;49(11-12):569-573.

12. Gurao NP, Sethuraman S, Suwas S. Effect of strain path change on the evolution of texture and microstructure during rolling of copper and nickel. Materials Science and Engineering: A. 2011;528(25-26):7739-7750.

13. Öztürk T. Deformation and recrystallization textures in crossrolled sheets of copper and $\alpha$-brass. Scripta Metallurgica. 1988;22(10):1611-1616.
14. Bhattacharjee PP, Joshi M, Chaudhary VP, Zaid M. The effect of starting grain size on the evolution of microstructure and texture in nickel during processing by cross-rolling. Materials Characterization. 2013;76:21-27.

15. Gurao NP, Ali A A, Suwas S. Study of texture evolution in metastable $\beta$-Ti alloy as a function of strain path and its effect on $\alpha$ transformation texture. Materials Science and Engineering: A. 2009;504(1-2):24-35.

16. Suwas S, Gurao NP, Development of microstructures and textures by cross rolling. In: Hashmi MJF, Ed. Comprehensive materials processing. Vol 3. Oxford: Elsevier; 2014. p. 81-106.

17. Pawlik K, Ozga P. LaboTex: the texture analysis software, Göttinger Arbeiten zur Geologie und Paläontologie. SB4; 1999.

18. Verlinder B, Driver J, Samajdar I, Doherty RD. Thermo-mechanical processing of metallic materials. London: Elsevier; 2007. 560 p.

19. Oda Y, Tanaka Y, Yamagami N, Chino A, Yamada K. Ultra-low Sulfur Non-oriented Electrical Steel Sheets for Highly Efficient Motors: NKB-CORE. NKK Technical Review. 2002;87:12-18.

20. Liu HT, Liu ZY, Sun Y, Qiu YQ, Li CG, Cao GM, et al. Formation of $\{001\}<510>$ recrystallization texture and magnetic property in strip casting non-oriented electrical steel. Materials Letters. 2012;81:65-68.

21. Liu HT, Schneider J, Li HL, Sun Y, Gao F, Lu HH, et al. Fabrication of high permeability non-oriented electrical steels by increasing $<00$ 1) recrystallization texture using compacted strip casting processes. Journal of Magnetism and Magnetic Materials. 2015;374:577-586. 